\title{
Investigating Near Surface S-Wave Velocity Properties Using Ambient Noise in Southwestern Taiwan
}

\author{
Chun-Hsiang Kuo ${ }^{1, *}$, Kuo-Liang Wen ${ }^{1,2}$, Che-Min $\operatorname{Lin}^{1}$, Strong Wen ${ }^{1}$, and Jyun-Yan Huang ${ }^{1,2}$ \\ ${ }^{1}$ National Center for Research on Earthquake Engineering, Taipei, Taiwan, R.O.C. \\ ${ }^{2}$ Institute of Geophysics, National Central University, Jhongli, Taiwan, R.O.C.
}

Received 24 December 2013, revised 18 June 2014, accepted 2 December 2014

\begin{abstract}
Ambient noise is typically used to estimate seismic site effects and velocity profiles instead of earthquake recordings, especially in areas with limited seismic data. The dominant Horizontal to Vertical Spectral Ratio (HVSR) frequency of ambient noise is correlated to Vs30, which is the average S-wave velocity in the top $30 \mathrm{~m}$. Vs30 is a widely used parameter for defining seismic amplification in earthquake engineering. HVSR can detect the vertical discontinuity of velocities, that is, the interfaces between hard bedrock and soft sediments. In southwestern Taiwan most strong motion stations are located in the plains and show a dominant frequency lower than $3 \mathrm{~Hz}$. Several stations near the coast have low dominant frequencies of less than $1 \mathrm{~Hz}$. The dominant frequencies are higher than $4 \mathrm{~Hz}$ at piedmont stations. The stations in the mountains with dominant frequencies over $8 \mathrm{~Hz}$ are typically located on very hard sites. This study analyzed the HVSR characteristics under different seismic site conditions considering the Vs 30 from previous study (Kuo et al. 2012). The result implies that HVSRs are a better tool than Vs30 to classify the sites where bedrock is deeper than $30 \mathrm{~m}$. Furthermore, we found a linear correlation between Vs30 and dominant HVSR frequency which could be used as a proxy of Vs30. The Vs30 map in this area was derived using the Engineering Geological Database for Taiwan Strong Motion Instrumentation Program (EGDT). The comparable distribution pattern between the dominant frequency and Vs30 demonstrate that HVSR can recognize S-wave velocity properties at the shallow subsurface.
\end{abstract}

Key words: Ambient noise, Dominant frequency, EGDT, HVSR, Vs30

Citation: Kuo, C. H., K. L. Wen, C. M. Lin, S. Wen, and J. Y. Huang, 2015: Investigating near surface S-wave velocity properties using ambient noise in southwestern Taiwan. Terr. Atmos. Ocean. Sci., 26, 205-211, doi: 10.3319/TAO.2014.12.02.05(EOSI)

\section{INTRODUCTION}

Earthquakes generate seismic waves propagating from the crust to the surface. Traditionally, their analysis has been used to understand the structure of the Earth by seismologists. Earthquakes of large magnitudes produce seismic waves which sometimes are amplified when propagating into the near surface strata, resulting in devastating effects. Major site effects are due to seismic wave amplification caused by local unconsolidated sediments at specific frequencies during strong ground motions. This is an important issue in both seismology and earthquake engineering since stronger seismic waves after the amplification of the near surface sediments frequently cause destructive damage to buildings. The fact that different seismic site conditions

\footnotetext{
* Corresponding author

E-mail: chkuo@ncree.narl.org.tw
}

are able to cause varied site effects was first recognized in the $19^{\text {th }}$ century (Milne 1898). It was noted that "It is an easy matter to select two stations within 1000 feet of each other where the average range of horizontal motion at the one station shall be five times, and even ten times, greater than it is at the other". This implies that as consequence of site effect strong shaking differences can occur at nearby sites. Therefore, understanding the variations in the shallow subsurface is important for seismic hazard mitigation.

Ambient noises, also called microtremors or microseisms for the frequency bands at higher or lower than $1 \mathrm{~Hz}$, are caused by various natural and artificial signals. These signals always exist and thus the measurement duration could be considerably short in comparison with waiting for enough earthquakes. Array (e.g., Aki 1957; Capon 1969; Kuo et al. 2009; Lin et al. 2009) and single-station (Nakamura 1989; 
Wen et al. 2008) methods are two well-known approaches of ambient noise use to estimate $\mathrm{S}$-wave velocity profiles and natural frequencies of soils, respectively. After Nakamura (1989) proposed the Horizontal to Vertical Spectral Ratio (HVSR) method ambient noise became a popular tool to assess site response (e.g., Parolai et al. 2001; Del Monaco et al. 2013), that is, the resonance frequency and amplification factor at a specific site, especially for those areas with minimal earthquake records. Recently several studies have implemented numerical modeling of HVSR curve values as a function of frequencies to estimate $\mathrm{S}$-wave velocity profiles (e.g., Arai and Tokimatsu 2004; Castellaro and Mulargia 2009). In the Taiwan Strong Motion Instrumentation Program (TSMIP) framework an Engineering Geological Database (EGDT) was constructed by the National Center for Research on Earthquake Engineering (NCREE) and Central Weather Bureau (CWB). This database included data logged from over 400 stations. Drilled station site classification has also been accomplished (Kuo et al. 2011a, b, 2012) according to the Vs30-based criteria of the National Earthquake Reduction Program (NEHRP) (BSSC 2001). Vs30 or site classes were utilized as a simple parameter in engineering applications, for example, regarding the seismic site effect when applying peak ground motion prediction equations, although some studies considered that Vs30 is weakly correlated with the site amplification factor (e.g., Castellaro et al. 2008). Ambient noise measurements were carried out as part of this study at 74 free-field stations in the TSMIP in southwestern Taiwan

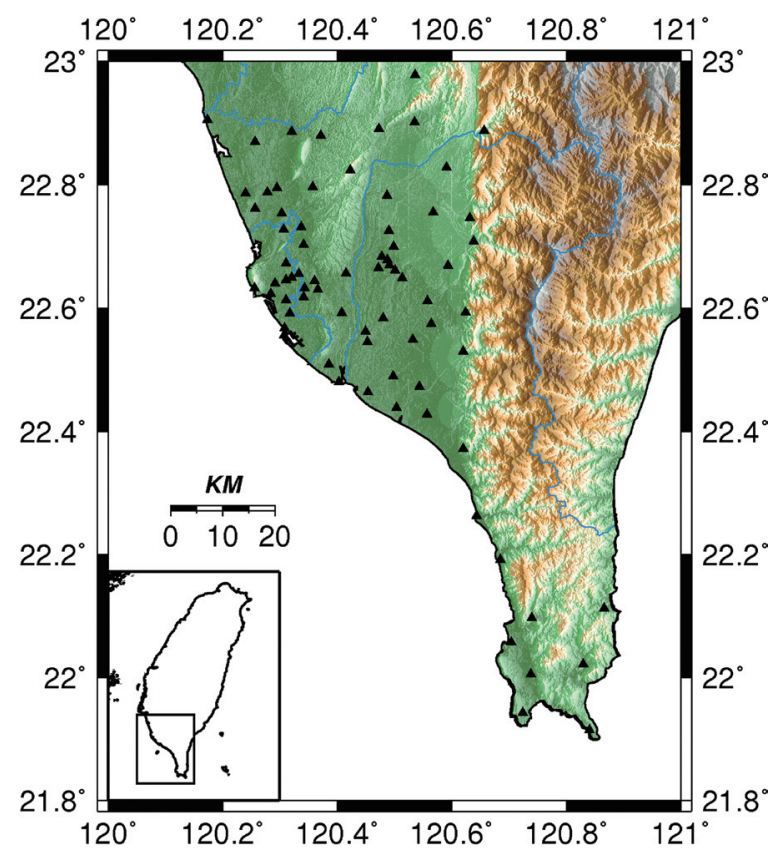

Fig. 1. Distributions of the free-field TSMIP (Taiwan Strong Motion Instrumentation Program) stations (black triangles) where the ambient noise measurements were conducted in southwestern Taiwan. The stations were mainly installed in the plains, especially in metropolitan areas.
(Kaohsiung and Pingtung areas) (Fig. 1). Numerous strong motion stations were investigated through a drilling project. It was found that Vs30 data is available from the EGDT in this area. We analyzed the correlation between the ambient noise and the subsurface $\mathrm{S}$-wave velocity variations by employing Vs30 as well as the ambient noise spectral ratios.

The study areas include Kaohsiung City and Pingtung County which are located north of the Western Foothills of Taiwan. The main geological formations outcropping in these areas, which comprise the Tashe Formation, Gutingkeng Formation, Linkou Conglomerate, Terrace Alluvium, and Holocene Alluvium, belong to Quaternary (Fig. 2). Others in the mountain area are Pliocene and Miocene. Most of the free-field TSMIP stations were distributed in the Pingtung Plain which is covered with unconsolidated alluvial sand and gravel deposits of recent age while Neogene rocks are distributed around the eastern plain border. Chiang (1971) indicated that the plain sediments thickness thins from west to east according to the data from seismic surveys, deep boreholes, and surface geology. Therefore, the subsurface layers in the Pingtung Plain can be assimilated into simple flat horizontal layers and we assume the potential 2D/3D effects (Haghshenas et al. 2008) that might complicate the HVSR properties are negligible in this study area.

\section{DATA ACQUISITION}

A 24-bit SAMTAC-801B recorder and six-channel

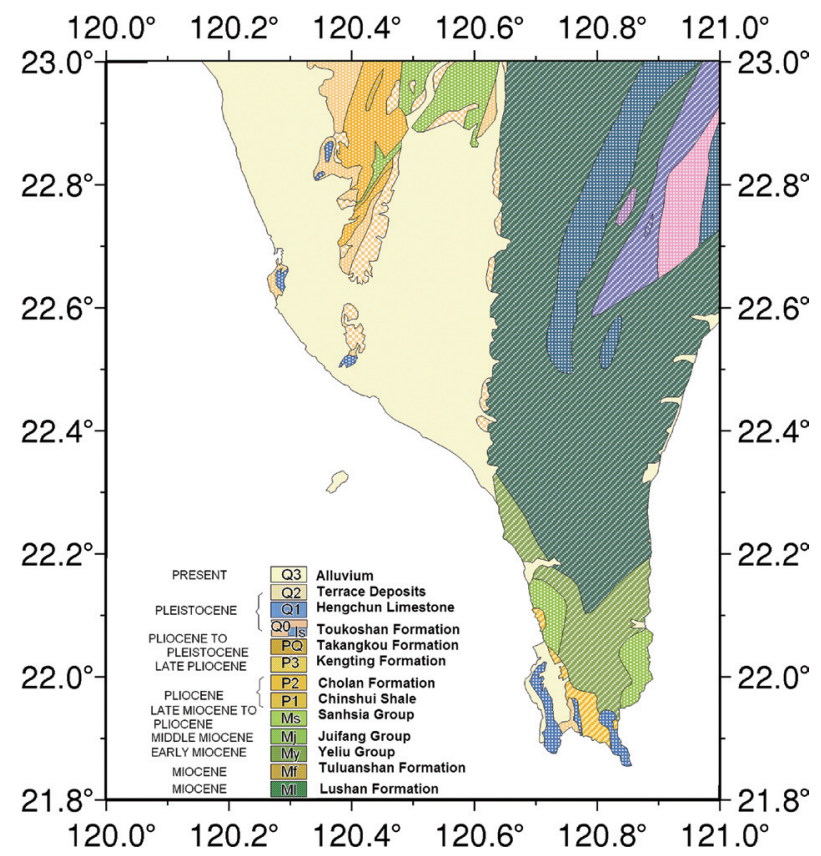

Fig. 2. Geological map of the Kaohsiung and Pingtung regions. Q2 and Q3 denote the Pingtung Plain covered by the Quaternary sediments. 
VSE311C sensor with flat amplitude from $0.1-50 \mathrm{~Hz}$ (manufactured by Tokyo Sokushin) were used to record ambient noise for this study. The sampling rate was set at 200 points per second with a recording period of 18 minutes for each measurement. The ambient noise measurements were conducted next to the strong motion stations in order to ensure that the geological conditions of the measurement sites are identical to those of the stations. Ambient noise recordings were partitioned into windows with a length of 8192 points (40.96 s) and a $6 \%$ cosine taper was implemented at both ends of each window. The recordings were checked and windows contaminated by exceptionally fluctuant noise were discarded in advance. The window number chosen for this study was above 20 to ensure that the averaged results are stable and reliable. The quadratic mean of the horizontal Fourier spectra was calculated, smoothed 5 times using the three-point average method and then divided by the smoothed vertical Fourier spectrum to derive a single-station HVSR, according to the expression:

HVSR $=\frac{\sqrt{\left(\mathrm{F}_{\mathrm{EW}}\right)^{2}+\left(\mathrm{F}_{\mathrm{NS}}\right)^{2}}}{\mathrm{~F}_{\mathrm{Vert}}}$

where $\mathrm{F}_{\mathrm{EW}}, \mathrm{F}_{\mathrm{NS}}$, and $\mathrm{F}_{\mathrm{Vert}}$ are the Fourier spectra in the eastwest, north-south and vertical directions. Averaging the HVSR from all time windows, the mean HVSR at a station was finally derived. The instrumental response function was thus eliminated during the procedure of the spectrum division.

Sites are commonly classified from the point of view of their response to seismic shaking based on Vs30 values. According to NEHRP's provision the hardest rock site is class $\mathrm{A}$, and the Vs30 at such a site must be higher than $1500 \mathrm{~m} \mathrm{~s}^{-1}$. A class B site has a Vs30 in the range of $760-1500 \mathrm{~m} \mathrm{~s}^{-1}$, which indicates a firm to hard rock site. A class $\mathrm{C}$ site is on dense soils or soft rocks with a Vs30 in the range of $360-760 \mathrm{~m} \mathrm{~s}^{-1}$. A class D site is located on stiff soils and has a Vs30 in the range of $180-360 \mathrm{~m} \mathrm{~s}^{-1}$. The Vs30 of a soft soil class E site is less than $180 \mathrm{~m} \mathrm{~s}^{-1}$. HVSR values obtained from ambient noise measurements were compared with Vs30 data derived from EGDT data. The velocity profiles down to about $32 \mathrm{~m}$ were measured using a suspension PS-logging system at the majority of stations in the region. At station KAU048 the depth is $11 \mathrm{~m}$ for the measured velocity profiles. However, N values obtained from Standard Penetration Tests carried out down to $15 \mathrm{~m}$ were used to correct Vs30 to $195 \mathrm{~m} \mathrm{~s}^{-1}$ due to the larger $\mathrm{N}$-value at the bottom of the borehole, and thus the site was reclassified from classes $\mathrm{E}$ to D. Unlike other stations that were investigated in the study of Kuo et al. (2012), a suspension PS-logging system was not used to measure the velocity at KAU086. Instead, the S-wave velocity profile was calculated using the $\mathrm{N}$-value profile via an empirical equation proposed by Kuo et al. (2012). The calculated Vs 30 at this station is $213 \mathrm{~m} \mathrm{~s}^{-1}$ and thus classified as class D. The Vs 30 at a total of 62 stations are available in southwestern Taiwan including 6 class B stations, 10 class C stations, 44 class D stations, and 2 class E stations.

Most of the strong motion stations in southwestern Taiwan are located in the plains and are classified as classes D or $\mathrm{E}$ without significant variations in the $\mathrm{S}$-wave velocity at a depth of less than $30 \mathrm{~m}$. Class $\mathrm{C}$ stations are distributed mainly in piedmonts with larger S-wave velocity variations in the near surface. The class B stations have relatively low velocity in the velocity range of this class. Vs 30 values are below $1000 \mathrm{~m} \mathrm{~s}^{-1}$ at 5 stations and higher than $1000 \mathrm{~m} \mathrm{~s}^{-1}$ at only one station. Figure 3 shows the cumulative percentage, for velocity steps of $50 \mathrm{~m} \mathrm{~s}^{-1}$, of sites with different average S-wave velocities down to four different depths, i.e., 5, 10, 20, and 30 $\mathrm{m}$, in this area. The highest cumulative rate is in the range of $150-300 \mathrm{~m} \mathrm{~s}^{-1}$, indicating that the percentages of classes D and $\mathrm{E}$ are more than $70 \%$. The divergence of the average $\mathrm{S}$ wave velocities in this range is inconspicuous. This suggests that no significant velocity increase with depth is present at classes D and E sites. A more substantial divergence of the average $\mathrm{S}$-wave velocities with depth is observed in the range $350-600 \mathrm{~m} \mathrm{~s}^{-1}$. This indicates that the S-wave velocity of class C sites increases substantially from depths of 5 to $30 \mathrm{~m}$. This figure also shows that the number of classes $\mathrm{C}$ and $\mathrm{D}$ stations is larger than that of classes B and $\mathrm{E}$ stations.

\section{PROPERTIES OF AMBIENT NOISE}

HVSRs at the investigated strong motion stations were derived in accordance to the standard data processing steps introduced in the above section except for the station KAU054 (class C) where a typhoon forced the closure of the road. In this stage, only 61 of the 74 HVSRs were plotted using different colors according to the Vs30 from the logging data (Fig. 4). The resonant peaks of stations increase in frequency with increasing Vs30. Moreover, these HVSR curves were categorized into classes B, C, D, and E according to the site classification system of Kuo et al. (2012), taking into account the corrections at the two stations based on the $\mathrm{N}$-values (Fig. 5). Some class B stations are situated on hard rocks, sometimes covered with a thin regolith layer and therefore the resonant HVSR peaks are unremarkable or at relatively higher frequencies with stronger amplifications. The class $\mathrm{C}$ stations which are located on soft rocks or stiff soils, have noticeable amplification at comparatively lower resonant frequencies than class B. The HVSRs of classes D and $\mathrm{E}$ are evidently amplified at the resonant frequencies of around $1 \mathrm{~Hz}$, which is relatively lower than that of classes B and C. In summary, similarities of HVSRs in each class are well defined as are the discrepancies between different classes.

Figure 6 shows the average HVSR values for the four classes: the differences in the curves and the dominant frequencies of each class are clear. The resonant frequency of class $\mathrm{B}$ is higher than that of class $\mathrm{C}$; class $\mathrm{C}$ is higher than 
class $\mathrm{D}$, and the resonant frequency of class $\mathrm{E}$ is clearly the lowest. The largest amplification was found in class $\mathrm{E}$ while class $\mathrm{C}$ showed the lowest amplification. However, the HVSR of class E is only available at two stations, thus the average HVSR for this class may be adjustable if HVSRs at more class E sites are available in this area.

\section{DISCUSSION}

A comparison between HVSR and Vs30 values obtained for southwestern Taiwan sites shows a clear correlation characterized by a linear trend (Fig. 7). We further carried out a linear regression for the data and obtained the result for Vs30 $=49.66 \mathrm{Fo}+182.29$, where Fo is the dominant HVSR frequency with a determination coefficient of 0.84 . The line corresponding to the regression equation is shown in Fig. 7 as a black solid line with 95\% confidence intervals represented by black dashed lines. Although the data sets show obvious scattering the above regression result can be a proxy of Vs30 using HVSR. The dominant frequencies for classes B and C overlap at around $9-10 \mathrm{~Hz}$, and classes $\mathrm{C}$ and D overlap at around 3 - $5 \mathrm{~Hz}$. For the class E sites, which are very few so that the Fo range for this class is not well constrained, the dominant frequencies are distributed within the class D range. It should be noted that the HVSR resonant peak frequency can assist in distinguishing the seismic site condition.

The Vs30 map of the research area shown in Fig. 8 uses the site classification result of Kuo et al. (2012). The map also includes several stations in Tainan and Taitung to cover a wider area in this contour range. Figure 9 shows the dominant HVSR frequency map of ambient noise measured at

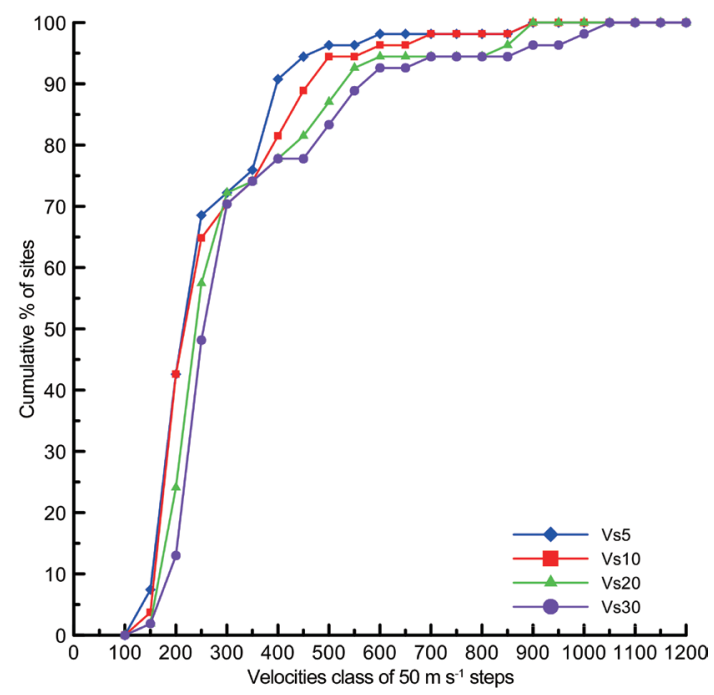

Fig. 3. Cumulative percentage of sites with different average $\mathrm{S}$-wave velocities down to four different depths: 5, 10 , 20 , and $30 \mathrm{~m}$. Velocity data of different depths are also from EGDT (Kuo et al. 2012).
74 KAU (Kaohsiung and Pingtung station code) strong motion stations. The distribution pattern shown in Fig. 8 is similar to that in Fig. 1, so that Vs30 is believed correlated with topography (e.g., Wald and Allen 2007; Chiou and Youngs 2008; Allen and Wald 2009). Therefore, we speculate Vs30 can also be estimated using dominant frequency due to the similarity shown in Figs. 8 and 9 as well as the correlation shown in Fig. 7.

\section{CONCLUSIONS}

Ambient noise measurements in Kaohsiung and Pingtung were conducted considering the EGDT logging results to analyze the $\mathrm{S}$-wave velocity properties at the near surface. The dominant frequency contours are very similar to that of Vs30 and comparable with the topography. The dominant frequency is in the range of around $1-2.5 \mathrm{~Hz}$ in the plains with Vs30 values of $180-300 \mathrm{~m} \mathrm{~s}^{-1}$; over $4 \mathrm{~Hz}$ in the piedmont and mountainous areas with Vs30 values higher than $360 \mathrm{~m} \mathrm{~s}^{-1}$; at several sites near the coast is lower than $1 \mathrm{~Hz}$ with Vs30 values ranging between $100-240 \mathrm{~m}$ $\mathrm{s}^{-1}$. The resonant frequencies of class $\mathrm{B}$ ranges from $9-18$ $\mathrm{Hz}$; approximately $3-10 \mathrm{~Hz}$ for class $\mathrm{C}$; less than $5 \mathrm{~Hz}$ for class D; and approximately $1 \mathrm{~Hz}$ for class $\mathrm{E}$. The regression result (Vs30 $=49.66 \mathrm{Fo}+182.29)$ can be a fast assessment tool for Vs30 although the data show obvious scattering. The largest amplification was found in class E while class C showed the lowest amplification. Classes B and D showed similar amplifications. In addition, all of the classes may have a wide amplification factor range. We therefore concluded that no obvious relation between the amplification of HVSR ambient noise and Vs30.

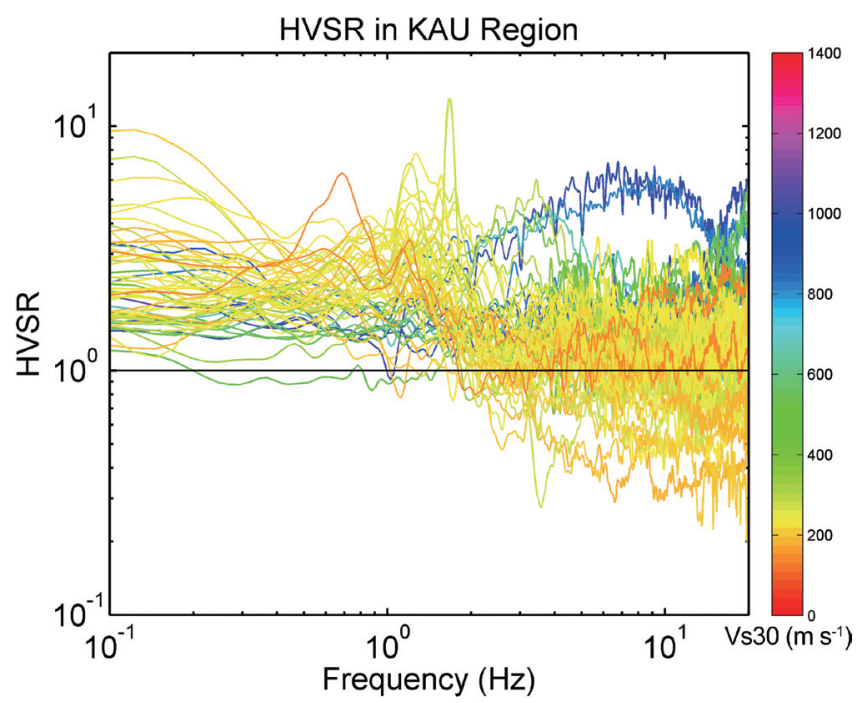

Fig. 4. HVSR of the 61 measured stations under different seismic site conditions with colors of corresponding Vs30. Two red curves are class E sites; yellow means class D sites; green denotes class C sites; blue indicates class B sites. 

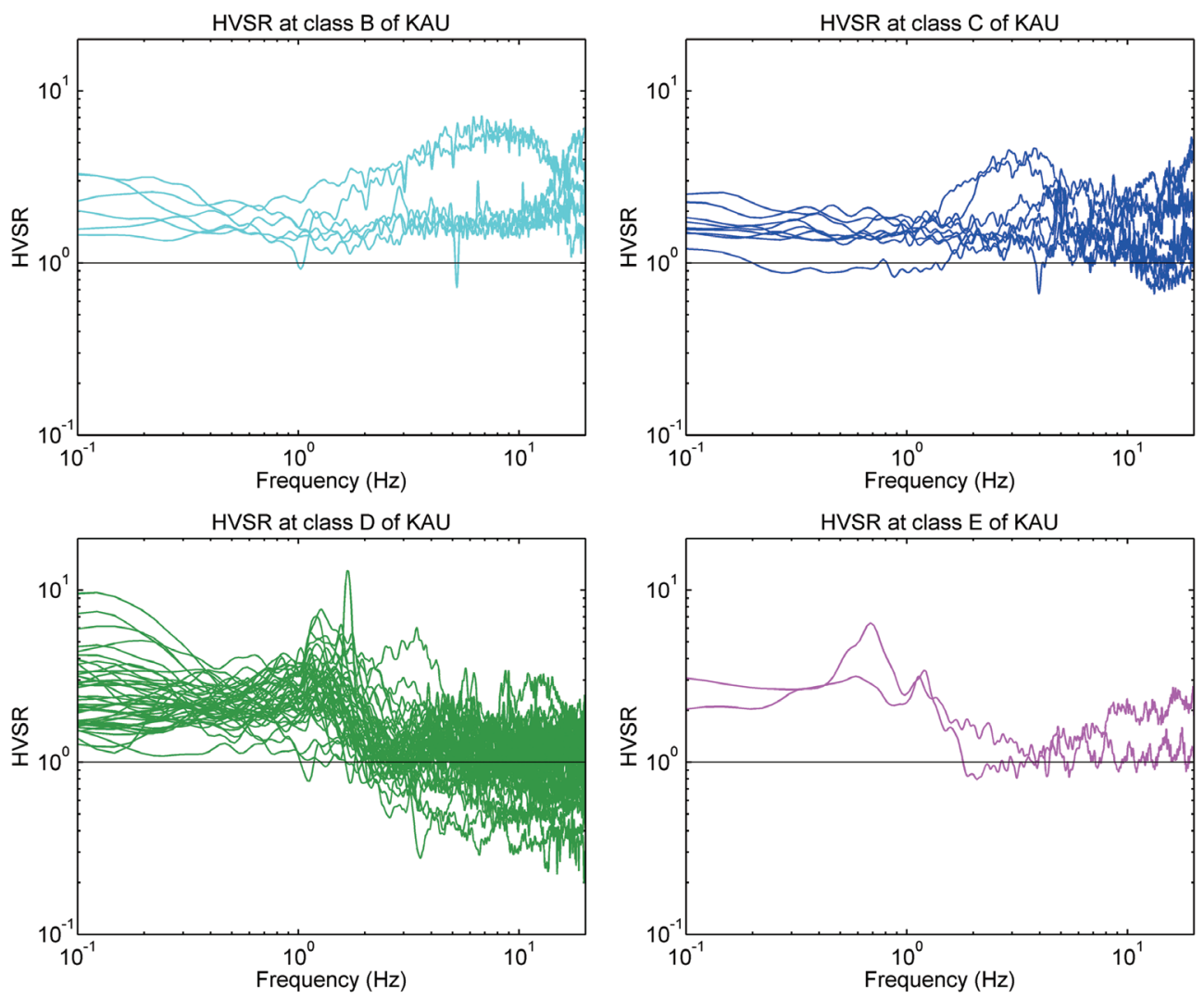

Fig. 5. The categorized HVSR (Horizontal to Vertical Spectral Ratio) curves according to the site classification system of Kuo et al. (2012). From upper left are class B HVSR curves, upper right indicates class C, class D in the lower left, and lower right shows class E.

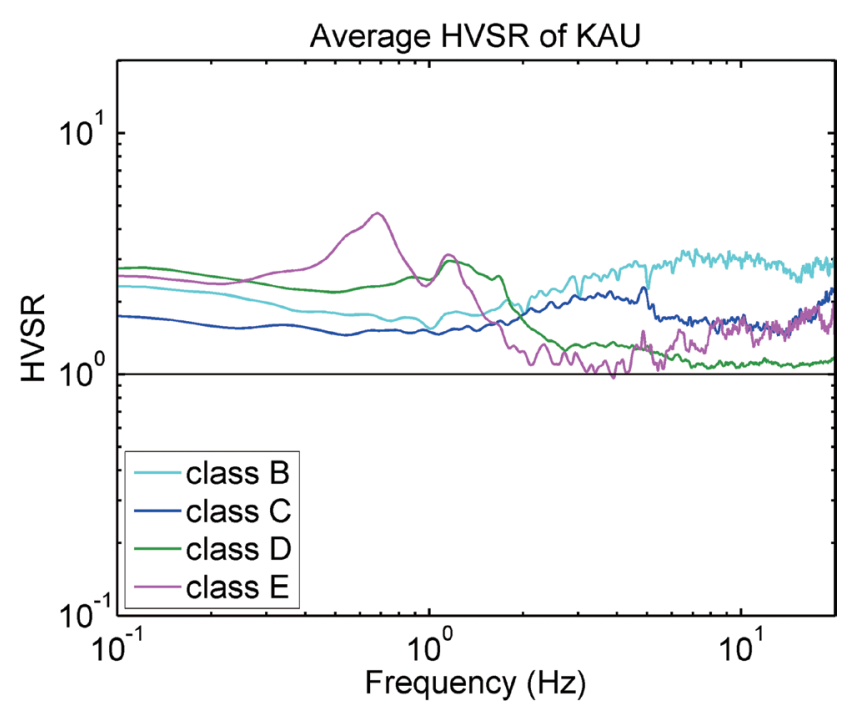

Fig. 6. HVSRs averages of site classes B, C, D, and E, respectively.

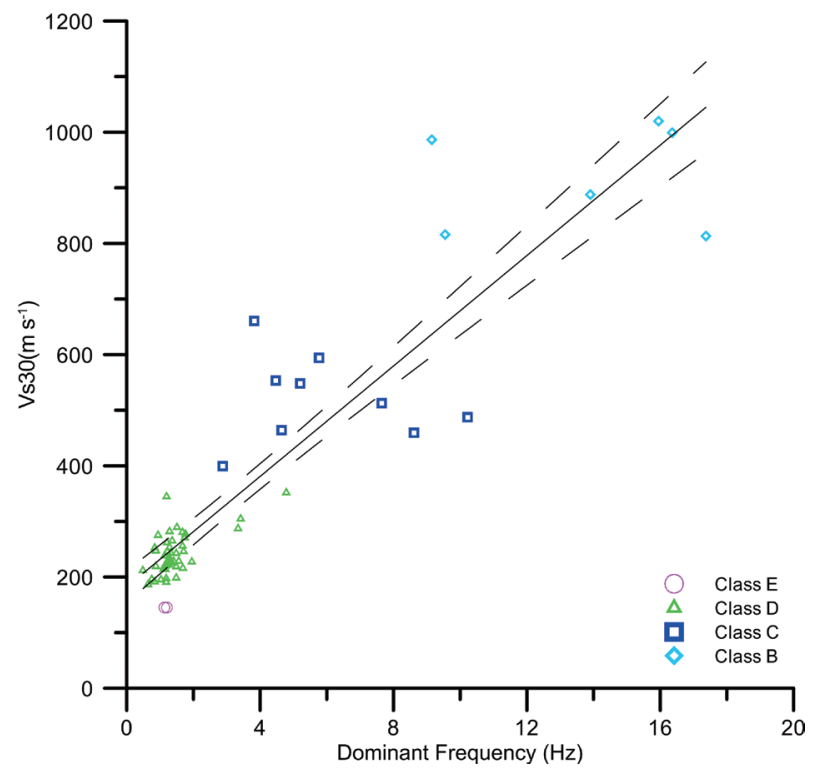

Fig. 7. Correlation between Vs30 and dominant frequency. Diamonds denote class $\mathrm{B}$, squares denote class $\mathrm{C}$, triangles denote class $\mathrm{D}$, and circles denote class $\mathrm{E}$. The resonant frequency shows a tangential linear increase with the Vs30. A linear regression resulted in equation Vs $30=49.66 \mathrm{Fo}+182.29$ plotted as a black solid line with $95 \%$ confidence intervals (black dash line). 


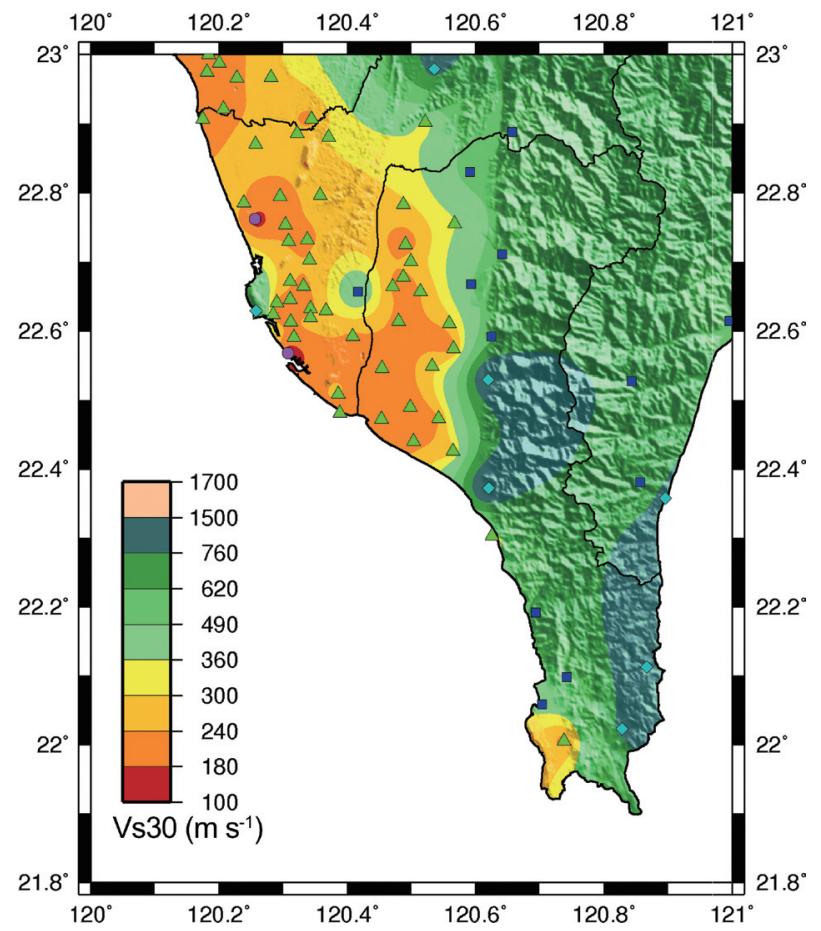

Fig. 8. Vs30 map derived from the EGDT data. Several stations in Tainan and Taitung were also considered in this map in order to cover a wider area. The measurement site classification symbols are the same as in Fig. 6.

The similarity between Vs30 and dominant frequency distributions indicates that the depth variations of the interface between a soft shallower layer and a stiffer substratum can be detected by observing the dominant frequencies of ambient noise. When the sedimentary depth of a site is less than $30 \mathrm{~m}$, it could be classes B or C. On the contrary, when the sedimentary depth is above $30 \mathrm{~m}$, it may be classes $\mathrm{D}$ or E. The HVSRs indicate several stations with dominant frequencies lower than $1 \mathrm{~Hz}$ near the coast. However, one exception near the coast is the KAU003 station at the National Sun Yat-sen University. This location has a dominant frequency that is higher than $15 \mathrm{~Hz}$ due to the station location on limestone. The local observations of extremely low resonant frequencies were caused by the presence of very thick sediments whereas Vs30 does not seem sensitive to deeper interfaces between different velocity layers. This may imply that HVSRs are a better tool than Vs30 to classify the sites where bedrock is deeper than $30 \mathrm{~m}$. The distributions of Vs30 as well as the averaged HVSRs are able to be used in site amplification corrections of strong motion prediction studies.

Ambient noise is also believed to be a cost and time effective tool for investigating variations in S-wave velocities in the shallow subsurface. This study confirms that the dominant HVSR frequency varies with Vs30 and indicates that HVSR is a better tool than Vs30 to classify sites where the bedrock is deeper than $30 \mathrm{~m}$.

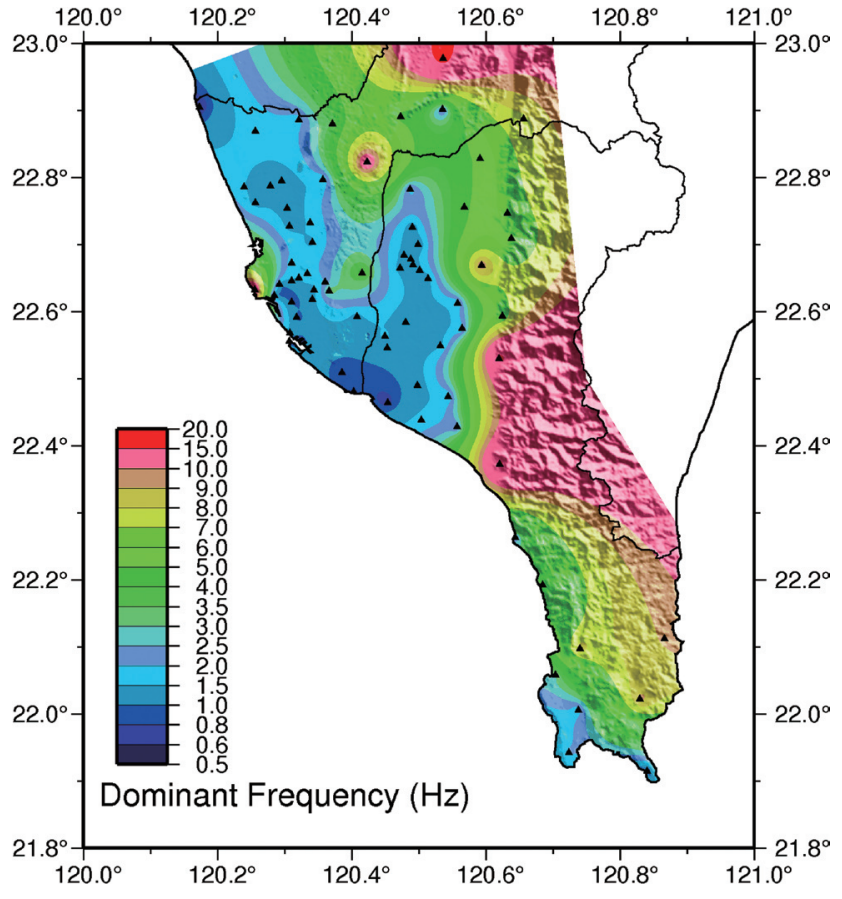

Fig. 9. Dominant frequency map plotted using the results of $74 \mathrm{KAU}$ strong motion stations where the ambient noise was measured. The black triangles are the measured station locations

Acknowledgements The authors offer many thanks to the members in the Strong Ground Motion Laboratory, Earth Science Department of National Central University in Taiwan for the field scheme and experiments. The authors also gratefully acknowledge the two anonymous Reviewer's great comments in completing this paper. This research was funded by the Ministry of Science and Technology (MOST), Taiwan, under the grant number NSC 102-2923M-492-001-MY3.

\section{REFERENCES}

Aki, K., 1957: Space and time spectra of stationary stochastic waves, with special reference to microtremors. Bull. Earthq. Res. Inst. Tokyo, 35, 415-456.

Allen, T. I. and D. J. Wald, 2009: On the use of high-resolution topographic data as a proxy for seismic site conditions $\left(V_{S 30}\right)$. Bull. Seismol. Soc. Am., 99, 935-943, doi: 10.1785/0120080255. [Link]

Arai, H. and K. Tokimatsu, 2004: $S$-wave velocity profiling by inversion of microtremor H/V spectrum. Bull. Seismol. Soc. Am., 94, 53-63, doi: 10.1785/0120030028. [Link]

Building Seismic Safety Council (BSSC), 2001: NEHRP Recommended Provisions for Seismic Regulations for New Buildings and Other Structures, Washington, DC. 
Capon, J., 1969: High-resolution frequency-wavenumber spectrum analysis. P. IEEE, 57, 1408-1418, doi: 10.1109/PROC.1969.7278. [Link]

Castellaro, S. and F. Mulargia, 2009: $V_{S 30}$ Estimates using constrained H/V measurements. Bull. Seismol. Soc. Am., 99, 761-773, doi: 10.1785/0120080179. [Link]

Castellaro, S., F. Mulargia, and P. L. Rossi, 2008: Vs30: Proxy for seismic amplification? Seismol. Res. Lett., 79, 540-543, doi: 10.1785/gssrl.79.4.540. [Link]

Chiang, S. C., 1971: Seismic study of the Chaochou structure, Pingtung, Taiwan. Petrol. Geol. Taiwan, 8, 281-294.

Chiou, B. S. J. and R. R. Youngs, 2008: NGA model for average horizontal component of peak ground motion and response spectra. PEER Report, Pacific Earthquake Engineering Research Center, University of California, Berkeley.

Del Monaco, F., M. Tallini, C. De Rose, and F. Durante, 2013: HVNSR Survey in historical downtown L'Aquila (central Italy): Site resonance properties vs. subsoil model. Eng. Geol., 158, 34-47, doi: 10.1016/j. enggeo.2013.03.008. [Link]

Haghshenas, E., P. Y. Bard, N. Theodulidis, K. Atakan, F. Cara, C. Cornou, G. Cultrera, G. Di Giulio, P. Dimitriu, D. Fäh, R. de Franco, A. Marcellini, M. Pagani, A. Rovelli, A. Savvaidis, A. Tento, S. Vidal, and S. Zacharopoulos, 2008: Empirical evaluation of microtremor H/V spectral ratio. Bull. Earthq. Eng., 6, 75-108, doi: 10.1007/s10518-007-9058-x. [Link]

Kuo, C. H., D. S. Cheng, H. H. Hsieh, T. M. Chang, H. J. Chiang, C. M. Lin, and K. L. Wen, 2009: Comparison of three different methods in investigating shallow shear-wave velocity structures in Ilan, Taiwan. Soil Dyn. Earthq. Eng., 29, 133-143, doi: 10.1016/j. soildyn.2008.01.010. [Link]

Kuo, C. H., K. L. Wen, H. H. Hsieh, C. M. Lin, and T. M. Chang, 2011a: Characteristics of near-surface S-wave velocity. National Center for Research on Earthquake Engineering, NCREE-11-022, 82 pp. (in Chinese)

Kuo, C. H., K. L. Wen, H. H. Hsieh, T. M. Chang, C. M. Lin, and C. T. Chen, 2011b: Evaluating empirical regression equations for $V s$ and estimating $V s 30$ in northeastern Taiwan. Soil Dyn. Earthq. Eng., 31, 431-439, doi: 10.1016/j.soildyn.2010.09.012. [Link]

Kuo, C. H., K. L. Wen, H. H. Hsieh, C. M. Lin, T. M. Chang, and K.W. Kuo, 2012: Site classification and Vs30 Estimation of free-field TSMIP stations using the logging data of EGDT. Eng. Geol., 129-130, 68-75, doi: 10.1016/j.enggeo.2012.01.013. [Link]

Lin, C. M., T. M. Chang, Y. C. Huang, H. J. Chiang, C. H. Kuo, and K. L. Wen, 2009: Shallow S-wave velocity structures in the western coastal plain of Taiwan. Terr. Atmos. Ocean. Sci., 20, 299-308, doi: 10.3319/ TAO.2007.12.10.01(T). [Link]

Milne, J., 1898: Seismology, Lodon, K. Paul, Trench, Trubner \& Co., Ltd. 345 pp.

Nakamura, Y., 1989: A method for dynamic characteristics estimation of subsurface using microtremor on the ground surface. Q. Rep. RTRI, 30, 25-33.

Parolai, S., P. Bormann, and C. Milkereit, 2001: Assessment of the natural frequency of the sedimentary cover in the cologne area (Germany) using noise measurements. J. Earthq. Eng., 5, 541-564, doi: 10.1142/ S1363246901000558. [Link]

Wald, D. J. and T. I. Allen, 2007: Topographic slope as a proxy for seismic site conditions and amplification. Bull. Seismol. Soc. Am., 97, 1379-1395, doi: 10.1785/0120060267. [Link]

Wen, K. L., C. M. Lin, H. J. Chiang, C. H. Kuo, Y. C. Huang, and H. C. Pu, 2008: Effect of surface geology on ground motions: The case of station TAP056 - Chutzuhu Site. Terr. Atmos. Ocean. Sci., 19, 451-462, doi: 10.3319/TAO.2008.19.5.451(T). [Link] 